\title{
Dogmatism, Learning and Scientific Pratices
}

\section{Marco Marletta}

\section{(2) OpenEdition \\ Journals}

Electronic version

URL: http://journals.openedition.org/ejpap/541

DOI: 10.4000/ejpap.541

ISSN: 2036-4091

\section{Publisher}

Associazione Pragma

\section{Electronic reference}

Marco Marletta, « Dogmatism, Learning and Scientific Pratices », European Journal of Pragmatism and American Philosophy [Online], V-2 | 2013, Online since 24 December 2013, connection on 19 April 2019. URL : http://journals.openedition.org/ejpap/541 ; DOI : 10.4000/ejpap.541

This text was automatically generated on 19 April 2019

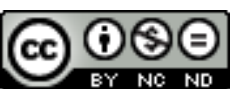

Author retains copyright and grants the European Journal of Pragmatism and American Philosophy right of first publication with the work simultaneously licensed under a Creative Commons AttributionNonCommercial-NoDerivatives 4.0 International License. 


\title{
Dogmatism, Learning and Scientific Pratices
}

\author{
Marco Marletta
}

\section{Introduction}

1 Philosophers of science have discussed the dichotomy between criticism and dogmatism in scientific practice since the 1960s. The core of their discussion regards the necessity to preserve the stability of science against "permanent (scientific) revolution" whilst at the same time, acknowledging the essential function played by doubt and criticism in scientific progress. Philosophers such as Thomas Kuhn stress the constitutive role of "normal science" in scientific practice, and affirm that criticism and doubt are appropriate only in exceptional circumstances, which he calls "crises", the prelude of revolutions. Popper and the Popperians reply that the development of science consists in the falsification of attested theories and that the suspension of doubt has negative consequences for science. The "Popper-Kuhn controversy" is recorded in Criticism and the Growth of Knowledge (Lakatos \& Musgrave, 1970), where Kuhn says, for example, that "Sir Karl has characterised the entire scientific enterprise in terms that apply only to its occasional revolutionary parts" (Kuhn, 1970: 6). Popper replies that, although normal science is a real phenomenon, it is also "a danger to science and, indeed to our civilisation" (Popper, 1970: 53). According to Popper, "the normal scientist [...] is a person one ought to be sorry for" (Popper, 1970: 52).

2 As we can see, the question deals with the social structure of science, and the nature of disagreement within scientific communities. Within what limits can scientists doubt the methods and results of their activities? It is trivial to say that a state of permanent doubt is dangerous for science, since it causes uncertainty, which can turn into scepticism and undermine the trust in scientific institutions (both among the experts and in the public debate about science). On the contrary, it is important for scientific communities to defend the stability of knowledge against pathological doubt and scepticism, and I think 
Popper would have agreed on this point. However, at the same time, we must acknowledge that the critical discussion of well-confirmed theories is an indispensable tool for the development of science. Therefore, it is useful to propose a model that distinguishes between useful doubt and pathological doubt about scientific practice.

I do not want to stir up the controversy on scientific dogmatism again, even though I think it is less radical than it seems to be. ${ }^{1}$ Nevertheless, many actors in this debate (Popper included) tend to discuss dogmatism as if it is merely a psychological or ethical attitude of the individual scientist, whereas I approach the question from a different viewpoint. I reconstruct the pragmatist and Wittgensteinian heritage of Kuhn's concept of dogmatism in order to clarify its function in scientific practice, and then it should be clear that both normal science and doubt are useful only from the social perspective of scientific communities and especially from Kuhn's analysis of the social nature of scientific training. I argue that this social dogmatism accounts for the rejection of meaningless doubts, which could harm knowledge, and justify the importance of criticism for scientific progress by allowing us to understand doubt from a communitarian standpoint.

4 I use a definition of dogmatism different to the common sense one and make a distinction between ordinary dogmatism and social dogmatism (the concept I want to endorse) which reflects the distinction between ordinary scepticism and organised scepticism. By organised scepticism, the sociologists of science mean that scientific theories should be tested and challenged by scientific communities. Organised scepticism, regulated by the norms of scientific method, responds to the precise demand for critical examination of knowledge: it is institutionalised scepticism (it is meaningful only from the social point of view of the scientific community and depends on peer judgement) which disqualifies the indiscriminate attacks on accepted theories and general knowledge. This distinction opposes the justified institutional scepticism to the personal sceptical attitude. My idea of social dogmatism is similar to this distinction. Ordinary dogmatism is the overconfident assertion of opinions and beliefs by an individual, regardless of contrary evidence and argument. On the contrary, by social dogmatism (from now on "dogmatism"), I mean blind (uncritical) adherence of a community to the "formal" system of norms and conventions, which constitutes its practice. It has nothing to do with the personal beliefs and opinions of individual scientists; rather, it deals with the self-regulation of human practices (in this case, scientific practice), since it self imposes the standard of correctness of such practices and, in turn, the methodological criteria of organised scepticism. In the following sections, I describe such systems of norm, the respective adherence, and its foundations, and refer to scientific practice from a Wittgensteinian and pragmatist point of view.

\section{Paradigms and their Normative Structure}

5 Since paradigms are the objects of scientific dogmatism, we should clarify them in order to understand Kuhn's dogmatism better. In his work following The Structure of Scientific Revolutions, he elaborates the concept of paradigm by differentiating its components. Since the "Postscript 1969", we find five elements composing a paradigm: ${ }^{2} 1$ ) symbolic generalisations; 2) methodological and heuristic models; 3) metaphysical models; 4) scientific values; 5) exemplars. In my argument, I focus on one and five. ${ }^{3}$ 
Symbolic generalisations are universal statements, expressed in formal language or easily formalised and used by the members of scientific communities "without question or dissent" (Kuhn, 1970: 182). We compare this element with the hard-core of Lakatos' scientific research programmes. We consider them the natural laws or the fundamental equation of the paradigm, such as $f=m a \circ I=V / R$, although we can express some in ordinary language (for example the first and third law of Newton's dynamics). These generalisations allow scientists to deal with scientific theories as mathematical constructions, so they justify the application of logical manipulations. However, symbolic generalisations do not specify how we apply them to nature.

In fact, we express the relationship between paradigm and nature by the most appropriated meaning of the term paradigm, i.e. exemplary case solution, "the concrete problem-solutions that students encounter from the start of their scientific education, whether in laboratories, in examinations, or at the end of chapters in science texts" (Kuhn, 1970b: 187). As they represent the concrete feature of scientific practice, Kuhn adds that exemplary problem solutions are the elements, which deeply determine the social nature of scientific practice, and the characteristic agreement within scientific communities, an issue I return to later. For Kuhn, the empirical content of scientific theories is localised only in exemplary cases. He says that an isolated symbolic generalisation is something "un-interpreted [...] empty of empirical meaning or application" (Kuhn, 1974: 299).

While abstract laws have no meaning, the connection between symbolic generalisation and exemplary cases constitutes the structure of scientific practice and is a normative structure. If we take Kuhn's rejection of the correspondence theory of truth ${ }^{4}$ and the comparison between Kuhn's paradigm and Wittgenstein's grammars ${ }^{5}$ for granted, it follows that the paradigms are not descriptive, but normative: "when engaged with a normal research problem, the scientist must premise current theory as the rules of his game" (Kuhn, 1970c: 270). ${ }^{6}$ They do not represent reality or facts and we cannot evaluate them through their accordance with reality; rather they are norms of representation, which determine a shared (by a scientific community) way of describing reality. ${ }^{7} \mathrm{~A}$ paradigm establishes the limits of meaningful scientific discourse, creates constraints for experience, and excludes possibilities. ${ }^{8}$ Kuhn's dogmatism consists in the "blind obedience" of scientists to the norms dictated by paradigms. In the following sections, I analyse the features of this obedience.

\section{Normativity, Contextuality, Learning}

9 It is important to stress again that the normative power of paradigm resides in the exemplary case solutions, while we can interpret symbolic generalisation in different ways. The relationship between symbolic generalisation and exemplary cases is necessarily circular. Exemplary cases are the application of universal laws, but universal laws are empirically meaningful only if connected to exemplary cases.

The pendulum, the inclined plane, and the rest are examples of $f=m a$, and it is being examples of $f=m a$ that makes them similar, like each other. Without having been exposed to them or some equivalents as examples of $f=m a$, students could not learn to see either the similarities between them or what it was to be a force or a mass; they could not, that is, acquire the concepts of force and mass or the meaning of the terms that name them (Kuhn, 1993: 247-8). 
of-chapter exercises in their textbooks, and says that universal laws apply to scientific practice because students do not learn symbolic generalisation in abstract terms, but by means of exemplary problem solutions. A paradigm is "a fundamental scientific achievement which includes both a theory and some exemplary applications to the results of experiment and observation" (Kuhn, 1963: 358). Referring to the scientific training experienced by physics students, Kuhn tries to break the circle between the two elements of the paradigm: the foundation of the normativity of paradigms is pragmatic, since it rests in scientific practice itself; it subordinates knowledge to practice and action. pragmatic approach and deflate the problem of the justification of norms saying that normativity has no metaphysical foundation. A grammar, or a paradigm, regulates the practice of a community, but the grammar has no foundation beyond its practice (Wittgenstein, 1958: 85). According to Kuhn's philosophy of science, the concrete scientific practice corresponds to exemplary case solutions. Kuhn enumerates some of them and affirms that almost all scientists start their education this way: "the inclined plane, the conical pendulum, and Keplerian orbits; instruments such as the vernier, the calorimeter, and the Wheatstone bridge" (Kuhn, 1970: 187). Thanks to these exemplary cases and to others that students face during training, they learn how to apply symbolic generalisations in new situations and problematic contexts using analogies with similar cases:

The student discovers, with or without the assistance of his instructor, a way to see his problem as like a problem he has already encountered. Having seen the resemblance, grasped the analogy between two or more distinct problems, he can inter-relate symbols and attach them to nature in the ways that have proved effective before (Kuhn, 1970b: 189).

Therefore, the first feature of scientific dogmatism is its contextual nature. Since symbolic generalisations are in themselves meaningless, their normative force is not independent of the actual practices of a scientific community. On the contrary, the meaning of scientific laws is contextually determined if we understand it on the horizon of a practice. As Wittgenstein said referring to rules, "a norm cannot work only by a formulation and interpretation, since we can reinterpret it in several ways" (Wittgenstein, 1976: 183); the rules acquire their normative content only if connected to particular practices of application. ${ }^{9}$ This idea fits well with Kuhn's interpretation of the second law of motion as analytic or quasi-analytic, or synthetic a priori proposition (Kuhn, 1989, 1990)::10 roughly, we can interpret the empirical content of Newton's law in different ways according to the role we want the law to play in scientific practice and to which terms we prefer to define empirically. Dogmatism makes possible such forms of contextual pragmatism, which implies that the ability to apply symbolic generalisations presumes a practical context, i.e. the consensus of the scientific community. This is a consensus of action, "a consensus of doing the same thing, reacting in the same way" (Wittgenstein, 1976: 183-4). Consensus is only possible thanks to training, since it is what we need if we want to understand a scientific (or linguistic) practice.

The second feature of scientific dogmatism is that it is a social phenomenon grounded in the relationship of confidence between student and teacher, which allows the student to join a scientific community. For both Kuhn and Wittgenstein, the agreement in action depends on the training process that we experience to understand and apply norms. They 
both refer to the pragmatist tradition, which focuses on the concepts of technique and skill to understand human practices and the structure and acquisition of concepts. ${ }^{11}$ As we can see, since the beginning of this essay, scientists use symbolic generalisations without question or dissent and employ them without allowing for alternatives. This attitude is the result of the training they receive, which according to Kuhn, is as rigid as in orthodox theology (Kuhn, 1970: 166). After all the students can only accept what the teacher and textbook present as the truth: "science students accept theories on the authority of teacher and text, not because of evidence. What alternatives have they, or what competence? The applications given in texts are not there as evidence but because learning them is part of learning the paradigm at the base of current practice" (Kuhn, 1970a: 80). Scientific training is authoritarian and cannot be otherwise since students lack the competence to evaluate and criticise what they learn. Consequently, the receptive attitude of the student (the blind acceptance of the authority of the teacher) is a prerequisite of the training. The process is successful if we accept the paradigm as the way we ought to do things. As will become clear, the paradigm itself partially dictates the results of an experiment and consequently, if an experiment goes wrong, "failure to achieve a solution discredits only the scientist and not the theory" (Kuhn, 1970a: 80). ${ }^{12}$

14 Finally, as the third preliminary feature of scientific dogmatism, I can only stress once again its connection to the social conception of science, i.e., the idea that the subjects of science are and must be scientific communities and not isolated scientists. ${ }^{13}$ This feature is already implicitly and explicitly contained in the second feature, since the learning process is necessarily a social process. In his comparison between scientific and linguistic training, Kuhn himself affirms that the acquisition of a (scientific) language is part of the socialisation procedure by which we make the scientist (or the child) part of the community and its world (Kuhn, 1974: 313). Referring to the social nature of paradigm and dogmatism, Kuhn quotes Wittgenstein again, and specifically refers to his rejection of the idea of "private language": "the very idea of scientific knowledge as a private product presents the same intrinsic problems as the notion of a private language [...] neither knowledge nor language remains the same when conceived as something an individual can possess and develop alone" (Kuhn, 1970d: 148). ${ }^{14}$ Clearly, scientists compose scientific communities, but a scientist is only really a scientist as a fellow of his scientific community, i.e. adherent to the paradigm. ${ }^{15}$

My first conclusion is that we have seen that scientists' dogmatic attitude towards the theories they support consists in the acceptance of a social practice regulated by a paradigm. We should not explain such an agreement within scientific communities by referring to the relationship between theory and reality, but rather find it in the constitutive role played by scientific training. In the following section, I focus on this pedagogical foundation of dogmatism.

\section{The Foundational Role of Scientific Training}

In the last section, we say that the extraordinary agreement within scientific communities depends on the common scientific training that scientists experience as students. Kuhn provides an original interpretation of the relationship between scientific training and scientific practice (Warwick \& Kaiser, 2005). ${ }^{16}$ First he notes that the normative power of paradigms does not rest upon explicit, coercive and inviolable rules, "the determination of shared paradigms is not, however, the determination of shared 
rules" (Kuhn, 1970a: 43). Sometimes we can abstract explicit rules by scientific practice, but normal science does not necessarily require an interpretation and rationalisation of paradigms: "normal science can be determined in part by the direct inspection of paradigms, a process that is often aided by but does not depend upon the formulation of rules and assumption" (Kuhn, 1970a: 44). Kuhn refers to Polanyi's tacit knowledge and Wittgenstein's family resemblance and I focus on the latter. In fact, I have just said that, according to Kuhn, the practice of normal science involves the mastery of similarity relationships, which allow the scientist to apply the paradigm-model in new problematic situations. Those similarities and regularities in application (often not expressed in explicit propositional form) provide the space to practice normal science, i.e. a space in which the actions and reactions of scientists agree. The training process entails that the teacher shapes the student's reactions, creating a common ground of agreement that we never question except in non-normal circumstances. The acquisition of concepts (intended as networks of similarities) is normative since the mastery of correct applications (which requires a "must") is constitutive of the concept itself.

Kuhn's most extended discussion of these matters is from everyday experience of language learning (Kuhn, 1974: 307-19). He considers a child, Johnny, who learns to distinguish different kinds of birds (ducks, geese, and swans) under the guidance of his father, during a walk. The father (who plays the role of the authority and supervisor of the correct usage in his community) uses ostension, and names the birds at which he points. When the child tries to do the same and identify the birds, the father validates or rejects the identification. Thanks to the guidance of his father, and after a certain number of correct identifications we can say that Johnny is competent in the identification of birds, ducks, geese, and swans, and that his instruction is successful. After the training Johnny applies these labels to nature, but he does not use anything like definitions or correspondence rules: "phrases like 'all swans are white' may play a role, but they need not" (Kuhn, 1974: 309); the child simply employs perception of similarities and differences. Kuhn's theory of the elaboration and acquisition of concepts is pragmatic, which means that the mastery of an empirical concept entails the correct use of the concept within the appropriate linguistic community (Hoyningen-Huene, 1993: 110).

Therefore, we constitute the conceptual structure that scientists share by similaritydifference classes associated to respective concepts without explicit definitions (i.e. without necessary and sufficient conditions of identification). They are family resemblances, and any scientist can legitimately use different criteria to identify a class, "in matching terms to their referents one may legitimately make use of anything one knows or believes about those referents" (Kuhn, 1983: 50). ${ }^{17}$ Kuhn's reference to the critique of the private language is now clearer. In order to share a language, the members of a scientific community need not share definitions or criteria of identification and application. What commensurable languages must preserve is only the structure of similarities and differences, which Kuhn calls "taxonomic or lexical structure", since the eighties:

What members of a language community share is homology of lexical structure. Their criteria need not be the same, for those they can learn from each other as needed. But their taxonomic structures must match, for where structure is different, the world is different, language is private, and communication ceases until one party acquires the language of the other; (Kuhn, 1983: 52) regulate by norms implicit in the lexical structure they acquire as students, and which 
"mirrors" aspects of the world it describes (and limits the phenomena described by the same lexicon). ${ }^{18}$ This observation leads to a second feature of scientific training that relates to the role played by exemplary problem solutions in the acquisition of the paradigm.

Together with the absence of explicit rules, there is a second important aspect of the relationship between scientific training and scientific practice. Kuhn draws attention to the difficulties faced by physics students to apply the physical laws presented in their textbooks (whose meaning they believed they had grasped perfectly) to solve the relative end-of-chapter exercises (Kuhn, 1970b: 179). Grasping the meaning of physical laws requires not only reflection on the structure of the laws themselves, but also the use of canonical exemplary solutions, which the scientific community considers correct. A consequence of this is that we reverse the relationship between exercises and laws. The normativity of paradigms lies in their exemplary nature. Therefore we do not use examples just to illustrate whether the student understands the lesson and the meaning of the terms that recur in physical laws; rather, examples generate the meaning of the same laws. Understanding is not a matter of adequate mental representations, it is the ability to use pre-existing solutions and examples to find a solution to new problems by means of new applications and articulations of the old terms. We do not define Newtonian concepts such as "force" or "mass" by the laws of motion, but by the experimental situation associated with such laws (for example the model of the inclined plane) (Kuhn, 1993: 147-8).

21 A consequence of this approach is that learning by means of examples is important not only to create common patterns of perception and action within scientific communities, but also to institute the connection between scientific language and reality. Training can (pragmatically) "found" normal science because it teaches students how to do things with language; once again, Kuhn follows Wittgenstein and emphasises that the meaning of scientific terms consists in their use in scientific practice. We learn the words that constitute a lexical structure in use, which implies that we acquire knowledge of language and knowledge of the world together:

Someone already adept in their use [of the scientific words] provides the learner with examples of their proper application. Several such exposures are always required, and their outcome is the acquisition of more than one concept. By the time the learning process has been completed, the learner has acquired knowledge not only of the concepts but also of the properties of the world to which they apply.

(Kuhn, 1993: 230)

Just like in language games where there are inextricably linked linguistic and nonlinguistic features, scientific training in paradigms is a nature-language learning (Kuhn, 1970c: 167), in relation to which, Kuhn explicitly speaks of "learning language and nature together" (Kuhn, 1970c: 171). ${ }^{19}$ As Wittgenstein says "the connection between words and things is set up by the teaching of language" (Wittgenstein, 1974: 97) and this kind of correlation is "simply the one set up by a chart, by ostensive gestures and simultaneous uttering of the name" (ibid). I return later to the role played by ostension in scientific training, but now I draw your attention to a consequence of the foundation of paradigms by means of learning by example. The lexical structure of scientific language is not something we can create abstractly and attach to reality; ${ }^{20}$ rather, Kuhn explains the connection between language and nature using the image of coinage with two faces: "the criteria relevant to categorisation are ipso facto the criteria that attach the names of those categories to the world. Language is a coinage with two faces, one looking outward 
to the world, the other inward to the world's reflection in the referential structure of the language" (Kuhn, 1981: 30).

Before I analyse two characteristic features of scientific training (ostension and the use of textbooks), I summarise the role of learning from previous reflections: ${ }^{21}$

a. Scientific training allows physics students to adhere to a social practice, characterised by a set of normative regularities, although we do not express these regularities by explicit and coercive norms.

b. Training requires a context whose background consents to the norms of the paradigm to be meaningful. The qualified teacher (the representative of the authority of a scientific community) provides this context: he approves or invalidates the behaviours of the students.

c. Just like every normative practice (a practice which asks for norms, standards, rules), scientific practice is necessarily social. We cannot consider a solitary man who does not support a paradigm a scientist, or, as Kuhn says, the results of his activity are something less than science.

d. The use of scientific concepts presupposes the mastery of their relative techniques and skills, but we cannot formalise such techniques and skills in a set of propositional norms, definitions, and rules of correspondence. The ultimate foundation of paradigms is pragmatic; it rests on scientific practice itself.

e. The general agreement pertaining to scientific communities (i.e. the fact that scientists do not usually question the basic elements of their discipline) originates from their adherence to the common patterns of behaviour and perception (networks of similarities and differences) acquired during training. Scientific dogmatism is grounded in the grammatical structure of paradigms.

\section{Ostension and Ostensive Learning}

Both Kuhn and Wittgenstein emphasise the role of ostension in the acquisition of a new (scientific) language; however, this idea requires clarification. Kuhn says that the exposition to examples of ostension is indispensable to understanding some scientific terms by direct application. It is part of the previously outlined process of contemporary acquisition of knowledge of language and nature. The objects involved in ostensive learning are not language-independent at all: just because we capture them by scientific practice, they have become, in Wittgenstein's words, "part of the symbolism" or "samples." "22 Clearly, this does not mean that ostension can fix the meaning of a word or generate a standard for future applications, or that ostensive definitions are adequate descriptions of the meaning of scientific terms. In Wittgenstein's philosophy of language, ostensive teaching (Wittgenstein, 1958: 4-5) plays the function of ostensive definition. This is to say the part of the training connected to the practice and context in which we embody the expression, helps the student to understand the use of a word and to establish a connection between language and things. ${ }^{23}$

Kuhn also acknowledges that ostensive definitions are not enough to fix the meaning of the words and distinguishes between "ostension" and "ostensive":

The terms "ostension" and "ostensive" seem to have two different uses, which for present purposes needs to be distinguished. In one, these terms imply that nothing but the exhibit of a word's referent is needed to learn or to define it. In the other, they imply only that some exhibit is required during the acquisition process. I shall, of course, be using the second sense of the terms. (Kuhn, 1989: 13) 
24

\section{wants to reaffirm that we do not learn scientific language regardless of the concrete use, and that ostensive learning is an important part, although only a part, of scientific training. While the use of everyday words such as "swan", "duck" and "goose" can create misunderstanding and induce the idea that the meaning of these terms is established by means of the ostensive act, the use of scientific terms immediately clarifies the question: \\ Pointing to a galvanometer needle while supplying the name of the cause of its deflection attaches the name only to the cause of that particular deflection (or perhaps to an unspecified subset of galvanometer deflections). It supplies no information at all about the many other sorts of events to which the name 'electric charge' also unambiguously refers. (Kuhn, 1979: 199)}

Kuhn's emphasis on ostension depends on his concept of learning through examples. He

y, referring to complex scientific terms, such as "electric charge", it is evident that Kuhn does not support the existence of ostensive definitions, but rather wants to stress the role of ostensive learning in the determination of the network of similarities and differences which constitutes the structure of scientific lexicon.

\section{The Authority of Scientific Textbooks}

In parallel with the relationship between teacher and students, Kuhn often notices that scientific textbooks represent the social authority of scientific communities in the training process. From the first page of The Structure of Scientific Revolutions, he says that the most common image of science derives from textbooks and from their pedagogical and persuasive power (Kuhn, 1970a: 1). Just as in ostensive learning, scientific textbooks also support the authoritative nature of the training: "readers of current science text accept the theories there expounded on the authority of the author and the scientific community" (Kuhn, 1961: 182-3), and not because they have experimentally tested such theories. In fact, Kuhn affirms that the experimental evidence presented in science texts almost has a pedagogical function, that is to say, they are exemplary solutions that enable an adequate understanding of the physical laws and their practical application. He refers to them as parts of a "context of pedagogy", different to both the context of discovery and the context of justification (Kuhn, 1977b: 327).

The context of pedagogy represented by science texts corresponds to the anti-historical and dogmatic attitude that Kuhn sees in scientific training. He points out that the most singular feature of scientific training is that we introduce science students to their respective discipline only through textbooks, while other students are encouraged to read the classics in their fields (Kuhn, 1963: 350). In contrast to other disciplines, the difference in alternative textbooks is mainly for technical and pedagogical details, but all display the same approach to their problem-fields (Kuhn, 1963: 350-1). This is because, in order to develop its characteristic dogmatism, scientific pedagogy voluntarily refuses a historical approach to its matter, ${ }^{24}$ which is not a criticism of scientific learning: science would probably not be possible without such ideas, a point I will return to. The question is to distinguish between the context of pedagogy and the history of science (and therefore the contexts of discovery and justification). ${ }^{25}$

The reference to the typical organisation of scientific knowledge in science texts according to the order of pedagogy highlights another aspect of scientific dogmatism: textbooks represent the product of the institutionalised scientific practice, i.e. a social self-authenticating practice that "justifies" the normativity of paradigms. ${ }^{26}$ The 
institutional structure of science, that is to say its social organisation through training, textbooks, scientific communities and so on, is a precondition for the organisation of meaningful scientific discourse. This is the nature of the paradigm, it creates and constrains the possibility of scientific practice. What is important for dogmatism is not the acceptance of particular beliefs, but the adherence to the "formal" normative structure of the paradigm. We can only consider what we learn in certain ways and from certain books approved by scientific communities to be scientific knowledge. ${ }^{27}$

\section{Dogmatism: A New Place for Doubt and Critique}

Dogmatism is not the scientists' psychological and ethical attitude towards the theories they work on, or the unjustified conviction in certain specified beliefs. It might be this way only if the paradigm is a conceptual schemes or a systems of propositions we believe to be true, but I argue that paradigms have nothing to do with the personal beliefs of scientists. On the contrary, paradigms have no descriptive nature, but rather a normative one, they are networks of rules for the production and organisation of scientific knowledge, i.e. of a set of consistent statements that we verify or falsify by means of experimental practice. Dogmatism does not refer to a system of beliefs, but to a system of norms, not to the specific content of knowledge but to the way scientific communities authenticate, organise, and transmit scientific knowledge. Although the way we organise knowledge inevitably influences the possible content of such knowledge (and so a distinction between formal and material aspects of knowledge is not satisfactory), paradigms are roughly, in a Kantian attitude, the formal matrix of our knowledge or a matrix for the construction of knowledge.

This is clear from referring to the interpretation of scientific changes. Let me concede for a moment, for the sake of the argument, the hypothesis that dogmatism is a psychological attitude of the individual scientist (or, as Popper says, a dangerous lack of critical approach). This hypothesis does not explain correctly, for example, the distinction between normal and revolutionary change in the history of science. In fact, one should not take the difference between normal and revolutionary science too literally and think that the characteristics of the former are completely opposite to the ones of the latter. ${ }^{28}$ Normal science is not a totally crystallised practice and it allows transformations and adjustments, which are sometimes substantial. According to the psychological-ethicalindividualist interpretation of dogmatism, (the scientist irrationally clings to his ideas and beliefs) we can interpret every change as revolutionary, since it requires a suspension of the dogmatic attitude. Kuhn tries to elaborate a more complex theory of revolutionary change by means of the distinction between the empirical features of scientific theories (the paradigm broadly speaking, as system of beliefs) and the normative features (the paradigm strictly speaking, as system of norms). A revolutionary change involves the normative backbone of scientific practice in depth, it is a substitution for the rules of the game: ${ }^{29}$

The problem of distinguishing between a core and an extended core has a close counterpart in my own work: the problem of distinguishing between normal and revolutionary change. I have here and there used the term "constitutive" in discussing that problem too, suggesting that what must be discarded during a revolutionary change is somehow a constitutive, rather than simply a contingent, part, or the previous theory. The difficulty, then, is to find ways to unpacking the term "constitutive". My closest approach to solution, still a mere aperçu, is the 
suggestion that constitutive elements are in some sense quasi-analytic, i.e. partially determined by the language in which nature is discussed rather than by nature tout court. (Kuhn, 1976: 187)

From the outset, we can see the role of scientific dogmatism links to the idea that some sections of scientific theories ("analytic, quasi-analytic or synthetic a priori" propositions, i.e. the symbolic generalisations connected to their applications in exemplary case solutions) behave as constitutive (and at least partially implicit) rules of scientific practice. These rules allow scientists to produce empirical propositions, open to criticism, doubt and empirical falsification, whereas, dogmatism deals with the blind adherence to the rules of scientific practice. ${ }^{30}$

Therefore, we do not intend the agreement within scientific communities to be conventionalist or relativist. It does not mean that what is true (or false) is the result of the conventional decision of the specialists and from that moment forward, we consider the result of such decisions unquestionable. Just like in Wittgenstein's famous affirmation, that is "not an agreement in opinion, but in forms of life" ${ }^{11}$ (Wittgenstein, 1958: 88) or "a consensus of action" (Wittgenstein, 1976: 183-4). ${ }^{32}$ The paradigms do not determine the truth, but the way scientists critically evaluate, discuss, test and challenge truths. Finally, Kuhn's dogmatism reveals a similarity with Wittgenstein's and pragmatists' conception of certainty, where accepting a proposition as certain means using it as a grammatical rule. ${ }^{33}$ An important point in this comparison is that both dogmatism and certainty are preconditions for meaningful doubts. In fact, when Kuhn enumerates the advantages of scientific dogmatism, along with the elimination of scepticism and pointless doubts, he says that scientists can recognise the failures and the problems of their theory only by referring to the background provided by the paradigm:

The practitioners of mature sciences know with considerable precision what sort of result he should gain from his research. As a consequence, he is in a particularly favourable position to recognise when a research problem has gone astray. [...] The practice of normal puzzle-solving science can and inevitably does lead to the isolation and recognition of anomaly. That recognition proves, I think, prerequisite for almost all discoveries of new sorts of phenomena and for all fundamental innovations in scientific theory. (Kuhn, 1963: 364-5)

This is what Kuhn calls the "essential tension" in scientific research (Kuhn, 1959). Scientific progress needs divergent and convergent thought, dogmatism and criticism, but we can understand the combined presence of these elements only from a social standpoint that acknowledges the centrality of scientific communities in the explanation of scientific development. Both dogmatism and criticism are meaningful only as social phenomena.

Consequently, dogmatism leaves space for criticism, except when it is necessary to avoid ceaseless scientific revolutions and theory changes that threaten scientific progress. It only safeguards the normative backbone of scientific theories from scepticism, saving this structure from the possibility of empirical falsification. Normally it involves only a few interrelated terms and laws, such as "mass", "force", "weight", the laws of motion etc., in Newton's physics. Except for this backbone, scientific assertions produced and organised through it, are subject to criticism, doubt, and rational discussion by means of the classical tools of experience, logic, evidence, persuasion and so on. These tools help scientists to determine what is true (and what is false), although obviously any theory choice involves decisional and fallible features. The paradigms (i.e. the things that shape scientific dogmatism) deal with the determination of what can or cannot be empirically 
true or false, that is to say, they are normative preconditions for the formation of meaningful scientific statements. ${ }^{34}$

\section{Conclusion}

In my paper, I argue that, in a scientific context, the distinction between meaningful doubt (which is positive for scientific progress) and pathological doubt (which turns into scepticism) is clear only from a social point of view about the nature of science and the organisation of scientific communities. Social dogmatism and organised scepticism are complementary concepts. On the one hand, organised scepticism guarantees the safety of scientific knowledge from sceptical and iconoclastic attacks, since it states that we regulate scientific doubt institutionally according to methods, criteria, and procedures established at the level of communities and subject to peer judgement. On the other hand, social dogmatism fixes the accepted methods, criteria and the procedures to practice science, and in turn, to exercise doubt and critical thinking. I stress again that such methods, criteria, and procedures are "formal concepts": they do not deal with the content of scientific knowledge, but with the organisation and production of scientific knowledge. They do not influence the truth, but the way scientists critically evaluate, discuss, test and challenge truths. In a scientific context, both dogmatism and scepticism are, at the same time, both dangerous and necessary. This does not mean that scientists should be simultaneously dogmatic and sceptical; rather, it means that certainty and nonpathological doubts emerge at the institutional level of scientific communities.

\section{BIBLIOGRAPHY}

ANDERSEN H., (2000a), “Kuhn's Account of Family Resemblance: A Solution to the Problem of WideOpen Texture”, Erkenntnis 52, 313-337.

ANDERSEN H., (2000b), “Learning by Ostension: Thomas Kuhn on Science Education”, Science and Education 9, 91-106.

Baltas A., (2004), "On the Grammar Aspects of Radical Scientific Discovery", Philosophia Scientiae $8,169-201$.

BARNES B. S., (1982), T. S. Kuhn and Social Science, London, Macmillan.

BIRD A., (2000), Thomas Kuhn, Chesham, Acumen Publishing.

BRANDOM R., (1994), Making it Explicit, Cambridge (Mass.), Harvard University Press.

CAVELL S., (1979), The Claim of Reason. Wittgenstein, Skepticism, Morality and Tragedy, Oxford, Oxford University Press.

CEDERBAum D. G., (1983), "Paradigms”, Studies in History and Philosophy of Science 14, 173-213. 


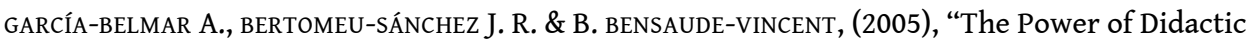
Writings: French Chemistry Textbooks in Nineteen Century”, in Kaiser A. ed., Pedagogy and the Practice of Science, Cambridge, The MIT Press, 219-52.

GLock H. J., (1996), “Necessity and Normativity”, in Sluga H. \& Stern G. eds., The Cambridge Companion to Wittgenstein, Cambridge, Cambridge University Press, 198-225.

HACKING I., (1982), “Language, Truth and Reason”, in Hollis M. \& Lukes S. eds., Rationality and Relativism, Cambridge (Mass.), MIT Press, 48-66.

HACKING I., (1993), “Working in a New World: The Taxonomic Solution”, in Horwich P. ed., World Changes. Thomas Kuhn and the Nature of Science, Cambridge (Mass.), MIT Press, 275-310.

HOYNINGEN-HUENE P., (1993), Reconstructing Scientific Revolutions. Thomas S. Kuhn's Philosophy of Science, Chicago and London, The University of Chicago Press.

IRZIK G. \& T. GRÜNBERG, (1998), “Whorfian Variations on Kantian Themes: Kuhn's Linguistic Turn”, Studies in History and Philosophy of Science 29, 207-21.

KINDI V., (2010), "Novelty and Revolution in Arts and Sciences: The Connection Between Kuhn and Cavell", Perspectives on Science 18, 284-310.

KUHN T., (1959), “The Essential Tension: Tradition and Innovation in Scientific Research”, in Taylor C. W. ed., The Third (1959) University of Utah Research Conference on the Identification of Creative Scientific Talent, Salt Lake City, University of Utah Press, 162-167, 169-174; reprinted in Kuhn (1977a), 225-39.

KUHN T., (1963), “The Function of Dogma in Scientific Research”, in Crombie A. ed., Scientific Change. Historical studies in the intellectual, social and technical invention, from a antiquity to the present , London, Heinemann Educational Books, 347-69.

KUHN T., (1970a), The Structure of Scientific Revolutions, 2nd revisited edition, International Encyclopedia of Unified Sciences, vol. 2, no. 2, Chicago and London, University of Chicago Press.

KUHN T., (1970b), “Postscript - 1969”, in Kuhn (1970a), 174-210.

KUHN T., (1970c), "Reflection on my Critics", in Lakatos I. \& Musgrave A. eds., Criticism and the Growth of Knowledge, Cambridge, Cambridge University Press, 231-278; reprinted in Kuhn (2000), 123-75.

KUHN T., (1970d), “Logic of Discovery or Psychology of Research?”, in Lakatos I. \& Musgrave A. eds., Criticism and the Growth of Knowledge, Cambridge, Cambridge University Press, 1- 23; reprinted in Kuhn (1977), 266-92.

KUHN T., (1974), "Second Thoughts on Paradigms", in Suppe F. ed., The Structure of Scientific Theories, Urbana - Chicago - London, University of Illinois Press, 459-82; reprinted in Kuhn (1977), 293-319.

KUHN T., (1976), “Theory Change as Structure Change: Comments on the Sneed Formalism”, Erkenntnis 10, 179-99; reprinted in Kuhn (2000), 176-95.

KUHN T., (1977a), The Essential Tension. Selected Studies in Scientific Tradition and Change, Chicago and London, University of Chicago Press.

KUHN T., (1977b), “Objectivity, Value Judgment, and Theory Choice”, in Kuhn (1977a), 320-39.

KUHN T., (1979), "Metaphor in Science", in Ortony A. ed., Metaphor and Thought, Cambridge, Cambridge University Press, 409-419; reprinted in Kuhn (2000), 196-207. 
KUHN T., (1981), “What are Scientific Revolutions?”, Occasional Paper \#18, Center for Cognitive Science, MIT; reprinted in Kuhn (2000), 13-32.

KUHN T., (1989), “Possible Worlds in History of Science”, in Allén S. ed., Possible Words in Humanities, Arts and Sciences, Berlin, De Gruyter, 9-32; reprinted in Kuhn (2000), 58-89.

KUHN T., (1990), “Dubbing and Redubbing: The Vulnerability of Rigid Designation”, in Savage C. W. ed., Scientific Theories, Minneapolis, University of Minnesota Press, 198-218.

KUHN T., (1991), “The Road Since Structure”, in Fine A., Forbes M. \& Wessels L. eds., PSA 1990: Proceedings of the 1990 Biennial Meeting of Philosophy of Science Association, Philosophy of Science Association, East Lansing, 3-13; reprinted in Kuhn (2000), 90-104.

KUHN T., (1993), “Afterwords”, in Horwich P. ed., World Changes. Thomas Kuhn and the Nature of Science, Cambridge, Massachusetts, MIT Press, 311-341; reprinted in Kuhn (2000), 224-52.

KUHN T., (2000), The Road Since Structure, Conant J. \& Haugeland J. ed., Chicago and London, University of Chicago Press.

LAKATOS I. \& A. MUSGRAVE, eds., (1970), Criticism and the Growth of Knowledge, Cambridge, Cambridge University Press.

MALONE M. E., (1993), “Kuhn Reconstructed: Incommensurability Without Relativism”, Studies in History and Philosophy of Science 24, 63-93.

MEDINA J., (2002), The Unity of Wittgenstein's Philosophy. Necessity, Intelligibility and Normativity, Albany, State University of New York Press.

POPPER K. R., (1970), “Normal Science and Its Dangers”, in Lakatos I. \& Musgrave A. eds., 51-8.

SANKEY H., (1997), “Kuhn's Ontological Relativism”, in Ginev D. \& Cohen R. S. eds., Issues and Images in the Philosophy of Science, Dordrecht, Kluwer Academic Publishers, 305-20.

SHARRock W. \& R. READ, (2002), Kuhn. Philosopher of Scientific Revolutions, Cambridge, Polity Press. WANG X., (2002), “Taxonomy, Truth-value Gaps and Incommensurability: A Reconstruction of Kuhn's Taxonomic Interpretation of Incommensurability", Studies in History and Philosophy of Science, 33, 465-85.

WARWicK A. \& D. KAISER, (2005), "Kuhn, Foucault and the Power of Pedagogy”, in Kaiser A. ed., Pedagogy and the Practice of Science, Cambridge, The MIT Press, 393-409.

WILLIAMS M., (1999), Wittgenstein, Mind and Meaning. Towards a social conception of mind, London, Routledge.

WitTGENSTEIN L., (1958), Philosophical Investigations, transl. G. E. M. Anscombe, Oxford, Basil Blackwell.

WITTGEnSTEIN L., (1969), On Certainty, transl. D. Paul \& G. E. M. Anscombe, Oxford, Basil Blackwell. WITTGENSTEIN L., (1974), Philosophical Grammar, Oxford, Basil Blackwell.

WITTGENSTEIN L., (1976), Wittgenstein's Lectures on the Foundations of Mathematics, Diamond C. ed., The Harvester Press, Hassocks.

WITTGENSTEIN L., (1978), Remarks on the Foundations of Mathematics, transl. G. E. M. Anscombe, Oxford, Basil Blackwell. 
WORRAL J., (2003), “Normal Science and Dogmatism, Paradigms and Progress: Kuhn 'versus' Popper and Lakatos", in Nickles T. ed., Thomas Kuhn, Cambridge, Cambridge University Press, 65-100.

\section{NOTES}

1. For a recent reconstruction of the debate between Popper and Kuhn, see Worrall (2003).

2. Or, better, a disciplinary matrix. See Kuhn (1970b: 175).

3. For a more extended treatment of the elements of a disciplinary matrix and their mutual relationships, see Hoyningen-Huene (1993: 145-59).

4. Bird (2000: 209-66).

5. Malone (1993); Glock (1996: 215); Sharrock, Read (2002: 162-3); Baltas (2004).

6. See also Kuhn (1970a: 52), where he used the expression "set of rules" to describe the paradigm.

7. As we will see in the following sections, this is not a form of instrumentalism which affirms that science has nothing to do with reality. The falsification or verification of empirical assertions depends on nature, but it is possible only taking for granted the practical horizon provided by the paradigm: paradigms are contitutive rules (for Kuhn's kantism, see HoyningenHuene 1993, and Irzik \& Grünberg 1998) which enable scientific practice.

8. "Here I cannot analyze in depth the normativity of paradigms. I recall an example by Kuhn himself: Dalton's law according to which atoms could only combine one-to-one or in some other simple whole number ratio. According to Kuhn it is not a true statement about the world, but, rather, it limits the field of meaningful propositions in chemistry: [It did] enable him to determine the sizes and weights of elementary particles, but it also made the law of constant proportion a tautology. For Dalton, any reaction in which the ingredients did not enter in fixed proportion was ipso facto not a purely chemical process. A law that experiment could not have established before Dalton's work, became, once that work was accepted, a constitutive principle that no single set of chemical measurements could have upset." (Kuhn, 1970a: 135).

9. See Medina (2002: 141-94) with reference to Wittgenstein contextualism.

10. On this matter Kuhn himself quotes Wittgesntein: Kuhn (1989: 72).

11. See for example Brandom (1994: $362 \mathrm{ff}$ ).

12. Wittgenstein says something consistent with this idea referring to arithmetical calculus. In fact it does not accept alternative results. If the result of a calculus is different of the attended one, you would say that "I must have made a mistake; the same kind of way would always have to produce the same result" (Wittgenstein, 1978: 70). This reply shows the mastery of a technique because "you are incorporating the result of the transformation into the kind of way the transforming is done" (ibid.).

13. For Kuhn, history and sociology of science are not variables which influence science from outside; rather science is essentially a social and historical enterprise (Kuhn, 1970c: 129-30).

14. See also Kuhn (1983: 52).

15. This reference to the critique of private language explain also a seemingly strange sentence from The Structure of Scientific Revolutions: "Anyone examining a survey of physical optics before Newton may well conclude that, though the field practitioners were scientists, the net result of their activity was something less than science" (Kuhn, 1970a: 13). The idea is that the public nature of paradigm pre-exists to the subjectivity of scientists and founds it. Moreover the social nature of science is emphasized also by the comparison between scientific communities and biological species. If scientific progress can be compared with Darwinian evolution, then the 
main characters of scientific progress are not individual scientists, but rather scientific communities. Kuhn develops this idea in his Kuhn (1991).

16. For other discussions of Thomas Kuhn's pedagogy of science, see Andersen (2000b) and Barnes (1982: 16-40).

17. See also Kuhn (1974: 307): "It is a truism that anything is similar to, and also different from, anything else. It depends, we usually say, on the criteria. To the man who speaks of similarity or of analogy, we therefore at once pose the question: similar with respect to what? In this case, however, that is just the question that must not be asked, for an answer would at once provide us with correspondence rules." For a discussion of Kuhn's conception of family resemblances and its differences with Wittgenstein's theory see Andersen (2000a).

18. The question of the relationship between paradigms and the world in Kuhn's philosophy of science is too much complex and discussed to be analyzed here. Therefore I refer to Hacking (1993), Hoyningen-Huene (1993), Sankey (1997).

19. On this matter Wittgenstein described some facts as "fused into the foundations of our language-game" (Wittgenstein, 1969: 73).

20. See Wittgenstein (1974: 89).

21. This summary is an adaptation of Meredith Williams's presentation of Wittgenstein's language learning theory to Kuhn's ideas about scientific learning (Williams, 1999: 214-5)

22. This means that the objects of ostensive learning begin playing a normative role to fix the meaning of some terms in their respective language-games.

23. For a distinction between ostensive definition and ostensive teaching, see Williams (1999: 21).

24. For example, the historical approach characterizes disciplines such as philosophy or arts.

25. Auguste Comte had already noted that the chronological order of scientific discoveries does not coincide with the actual organization of knowledge. Communicating and teaching the achievements of science require a certain reconstruction which produces a new order of the arguments and their mutual relationship (Comte called it "the dogmatic order") different of the order of discovery and justification ("the historical order"). Moreover on this matter, another predecessor of Kuhn is Gaston Bachelard, who has emphasized the role of textbook for scientific pedagogy and focused especially on their normative and social function. For a comparison between Comte, Bachelard and Kuhn on scientific pedagogy and textbooks see García-Belmar, Bertomeu-Sánchez, Bensaude-Vincent (2005: 219-22). As a final point, the philosopher of science who is closer to Kuhn in the analysis of scientific training is Ludwik Fleck; in fact he studied the authoritative and dogmatic nature of scientific learning and related it to the use of textbooks, intended as the principal instrument of that "indoctrination" (see Cederbaum, 1983: 195-6).

26. I have already sketched the social and normative nature of paradigms. Now I shortly describe their self-authentication: 1 ) the same experience-field can be often fixed by different paradigms (Kuhn, 1970a:76); 2) no paradigm can be said "grounded or justified by experience" (Kuhn, 1970a: 146-8). This is a common point between Kuhn's paradigms and Wittgenstein's grammar: they both can be justified only by a pragmatic point of view, since their normativity imposes the standards for their own justification (Kuhn, 1970a: 109-10).

27. Wittgenstein says that we believe scientific facts because they are transmitted to us "in a certain manner" (Wittgenstein, 1969: 24-5) and that in general we take as true "what is find in the textbooks" (Wittgenstein, 1969: 23). Finally we have no ground for trusting textbooks of experimental physics (Wittgenstein, 1969: 79).

28. Kuhn admits that in The Structure of Scientific Revolutions he himself had overly emphasized the normal-revolutionary science distinction and that if he were rewriting his book I would focus less on such distinction (Kuhn, 1983: 57).

29. Kuhn (1989: 72).

30. Of course, the distinction between empirical and normative propositions is not so sharp: it is not grounded in the empirical reality. Just like Wittgenstein, Kuhn does not distinguish two 
different kinds of proposition, but two different uses. The same proposition can be in certain circumstances an empirical proposition which we can test by experience and, in other circumstances, a normative proposition which we use as rule of testing (Wittgenstein, 1969: 15); but it cannot be at the same time an empirical and normative proposition.

31. In order to avoid the conventionalist problems related to the word "agreement", Stanley Cavell proposes to translate Wittgenstein's German word Übereinstimmung with the English "attunement" and not with the traditional "agreement". That is because "the idea of agreement here is not that of coming to or arriving at an agreement on a given occasion, but of being in agreement throughout, being in harmony, like pitches or tones, or clocks, or weighing scales, or columns of figures" (Cavell, 1978: 32). Cavell and Kuhn worked together at the University of Berkley and Cavell's interpretation of Wittgenstein could have been an important influence in Kuhn's understanding of the Austrian philosopher (see Kindi, 2010).

32. This reference to the agreement in action as an agreement in forms of life explains also a statements of The Structure of Scientific Revolutions which could be misunderstood. Kuhn wrote that the choice between competing paradigms "proves to be a chose between incompatible modes of social life" (Kuhn 1970a: 94). This idea could look like a relativist affirmation about the incomparability of scientific theories, together with an underestimation (or an exaltation) of the intolerance towards different ideas. Instead he says just that different paradigms correspond to different models of social action and, in the end, to different forms of life, but this does not involve considerations about relativism or intolerance.

33. Clearly this is closely related to the role played by such proposition in the learning process (Wittgenstein, 1969: 62).

34. See Hacking (1982) for a distinction between true-or-false statements and statements which are not candidates for truth-or-falsehood; this idea has already been applied to Kuhn's paradigms by Wang in his Wang (2002).

\section{ABSTRACTS}

In the traditional debate on the dichotomy between dogmatism and criticism in scientific practice (the Popper-Kuhn debate), dogmatism is considered a psychological or ethical attitude of the individual scientist. In this paper, I propose a new interpretation of scientific dogmatism by means of a reconstruction of the pragmatist and Wittgensteinian heritage of Kuhn's concept of dogmatism. My thesis is that such a revised concept accounts for both the stability of scientific knowledge (against scepticism and ceaseless scientific revolutions), and the importance of doubt and criticism for scientific progress. This is possible only if we consider dogmatism from a social perspective that focuses on scientific communities as the main actors in the history of science. From this point of view, dogmatism is not the unjustified acceptance of particular beliefs, but the blind adherence to the "formal" normative structure of the paradigm. I argue that we have grounded this normative structure in the training process that physics students experience in their formative years, and that Kuhn describes in a similar way to Wittgenstein's analysis of general linguistic training. Finally, dogmatism does not refer to a system of beliefs, but to a system of norms; not to the specific content of knowledge but to the way that scientific knowledge is authenticated, organised, and transmitted by scientific communities. The institutional structure of science, that is to say its social organisation trough training, textbooks, scientific communities and so on, is a precondition for the organisation of meaningful scientific 
discourse (i.e. for the production and organisation of empirically verifiable or falsifiable statements). That is the nature of the paradigm: it creates and constrains the possibilities of scientific practice. In normal circumstances, dogmatism and certainty are concerned with such pragmatic a priori, while criticism and doubt are concerned with the empirical statements articulated through it.

\section{AUTHOR}

\section{MARCO MARLETTA}

University of Palermo

marco.marletta[at]unipa.it 